\title{
Quando traduzir é (re)escrever (um)a história: o papel dos intérpretes na Comissão da Verdade na África do Sul
}

\author{
When translating is (re)writing a \\ story: the role of interpreters at the \\ Truth Commission in South Africa
}

\author{
Viviane Veras ${ }^{*}$ \\ - Nkosi sikelel' iAfrika ${ }^{1}$ \\ Nkosi sikelel' iAfrika \\ Maluphakanyisw' uphondo lwayo, \\ Yizwa imithandazo yethu, \\ Nkosi sikelela, thina lusapho lwayo. \\ Morena boloka setjhaba sa heso, \\ O fedise dintwa le matshwenyeho, \\ O se boloke, O se boloke setjhaba sa heso, \\ Setjhaba sa South Afrika - South Afrika. \\ Uit die blou van onse hemel, \\ Uit die diepte van ons see, \\ Oor ons ewige gebergtes, \\ Waar die kranse antwoord gee, \\ Sounds the call to come together, \\ And united we shall stand, \\ Let us live and strive for freedom, \\ In South Africa our land.
}

\footnotetext{
" Universidade Estadual de Campinas, UNICAMP, Programa de Pós-Graduação em Linguística aplicada. Email: viveras@iel.unicamp.br

${ }^{1}$ Ponho em epígrafe Nkosi sikelel' iAfrika (The call of South Africa), cantado em 5 línguas: xhosa, zulu, sesotho, africâner e inglês, para destacar que foi composto em 1897 e adotado como Hino Nacional um século depois.
} 
ABSTRACT: The South African Truth and Reconciliation Commission aims at making, by means of words, a smooth transition from the system of apartheid to democracy, seeking to elicit, in the testimony of victims/survivors, the truth and a possibility of reconciliation. This article discusses the role of translators and interpreters in (re)writing the history of South African people. Professionals are here both regarded as indispensable to the workings of the Commission insofar as they attested with their voices, whose echoes spread all over the country, that they are those who literally enabled the trans-mission of everything that would be registered and transcribed in the seven volumes of the TRC Report, which is the final document of a past period that gives way to democracy.

Keywords: interpreter, translation, history, South African Truth and Reconciliation Commission

Resumo: A Comissão da Verdade e Reconciliação da África do Sul tem por objetivo fazer, com palavras, uma transição pacífica do regime do apartheid para a democracia, buscando no relato das vítimas/sobreviventes e dos autores de graves crimes contra a humanidade, uma verdade e uma possibilidade de reconciliação. Este trabalho discute o papel dos tradutores e intérpretes na (re)escrita da história do povo sul-africano. Esses profissionais são tomados aqui como testemunhas imprescindíveis para a realização dos trabalhos da Comissão, atestando com suas vozes, que se espalham por todas as comunidades do país, que são eles que tornam possível, literalmente, a trans-missão de tudo o que vai ser registrado e transcrito para integrar os sete volumes do relatório final (TRC Report), construindo o arquivo do passado que dá lugar à democracia.

PALAVRAS-CHAVE: intérprete, tradução, história, Comissão da verdade e Reconciliação da África do Sul 
A palavra africâner apartheid (do holandês apart - separado + heid - em inglês hood), nomeava o sistema de leis e políticas de proteção às pessoas brancas, a segregação do povo sul-africano com base na raça (classe social e, acrescento, línguas), controlando o deslocamento, as formas de trabalho, de convivência e de casamento entre pessoas de raças e etnias diversas. Como somente os brancos podiam ocupar os centros das cidades e certos bairros, o sistema acabou por construir e manter a cultura do township ${ }^{1}$ (favela), caracterizada também pelos estilos musicais, maneiras de se vestir e de viver sua sexualidade.

Em vigor desde 1909, o apartheid ganha letras de lei em 1948, consolidando a dominação branca (pessoa evidentemente branca ou aceita como tal) sobre todas as pessoas denominadas não-brancas (negros - natives, asiáticos, mestiços - coloured) até 1994, apesar das várias formas de resistência a esse regime nos anos 1950, que endureceram muito a partir dos anos 1970. O fim do apartheid - sistema de poder considerado por instituições e autoridades internacionais um crime contra a humanidade - assinala uma profunda mudança no país, que vai ter a garantia de uma transição relativamente pacífica para o novo regime democrático com 0 estabelecimento da Comissão da Verdade e Reconciliação [Truth Reconciliation Commission] em dezembro de 1995. As sessões públicas tiveram início na cidade sul-africana East London, em 15 de abril de 1996, tendo se encerrado em outubro de 1998 , com o envio do Relatório ${ }^{2}$ a Nelson Mandela.

Considerada a mais eficaz das iniciativas de reconciliação e de justiça, a Comissão teve seus trabalhos marcados por episódios dramáticos e carregados de emoção. Inscreveram-se 21.290 vítimas, das quais 19.050 foram

\footnotetext{
${ }^{1}$ Cf. "Raça", ressentimento e racismo: transformações na África do Sul de Thomas Blaser; Brigitte Bagnol; Zethu Matebeni; Anne Simon; e Sandra Manuel, em Cadernos Pagu (2010). Anne Simon é conferencista do Departamento de Estudos de tradução e de interpretação na Universidade de Witwatersrand, Johannesburgo, África do Sul.

${ }^{2}$ Os 7 volumes da TRC Report estão disponíveis em http://www.justice.gov.za/trc/ report/index.htm e os 86 episódios reunidos pelo jornalista Max Du Preez podem ser encontrados em vídeo com interpretação simultânea (voice-over) ou legendados, no site da Yale School of Law http://trc.law.yale.edu/video_episodes. htm Acesso em julho de 2008.
} 
VERAS, V. Quando traduzir é (re)escrever (um)a história

declaradas vítimas de "graves violações dos direitos humanos". Vieram dar ser testemunho 2.200 sobreviventes. Quanto às demandas de anistia, houve 7.116 pedidos, dos quais 1312 foram concedidos e 5.143 rejeitados ${ }^{3}$. A despeito dessa brutal estatística, o próprio relatório afirma, no início do volume I, que "a narrativa conta apenas uma pequena parte do uma história muito mais ampla de abuso dos direitos humanos na África do Sul” (p.24).

Com base na reforma política de 1994, e na legitimação constitucional de 12 línguas oficiais ${ }^{4}$ - Ndebele, Xhosa, Shoto, Shoto do Norte, Tswana, Swati, Venda, Tsonga, Zulu, Africâner, Inglês, Língua Africana de Sinais - o texto da Comissão (Truth Reconciliation Commission - TRC Report) determina que ninguém seja discriminado com base na língua que fala.

Oferecendo às vítimas um local em que pudessem contar suas histórias em suas próprias línguas, a Comissão não só ajudou a revelar fatos reais sobre abusos do passado, mas auxiliou também na criação de uma 'verdade narrativa'. Assim fazendo, ela também procurou contribuir para o processo de reconciliação, garantindo que a verdade sobre o passado incluísse a validação das experiências subjetivas individuais de pessoas que haviam sido previamente silenciadas. (TRC. Vol. 1, cap. 5, p. 112)

A Comissão Sul-Africana de Verdade e Reconciliação é composta, então, de três comitês: o Comitê de Violações dos Direitos Humanos (primeiros seis meses do trabalho na Comissão) - que começa pela escuta das narrativas das vítimas, seguidas dos depoimentos dos torturadores - dirigidos ao Comitê de Anistia. O objetivo do Comitê de Reparações e Reabilitações seria elaborar e fazer valer um sistema de compensações para as vítimas de tortura (o sistema deixou e deixa, até hoje, muito a desejar).

\footnotetext{
${ }^{3}$ As estatísticas estão detalhadas por região, gênero, idade, etc. TRC Report, v. I, cap. 6. Disponível em http://www.justice.gov.za/trc/report/finalreport/Volume\%201.pdf As traduções de trechos do Relatório e todas as traduções não referenciadas são de minha responsabilidade. Para trechos em inglês valho-me do The American Heritage Dictionary of the English Language (2000)

${ }^{4} \mathrm{Na}$ maioria dos textos consultados são 11 línguas, mas Annelie Lotriet (2001) registra também a Língua de Sinais Sul-Africana (South African Sign Language), também reconhecida como língua oficial na nova Constituição.
} 
VERAS, V. Quando traduzir é (re)escrever (um)a história

Nos trabalhos da Comissão, tudo passa pela mediação dos 17 comissários, que conduzem os trabalhos, e pelos intérpretes - muitas vezes em mais de uma língua. Protagonistas, e não somente mediadores, os intérpretes assumem a posição seja de vítima seja de perpetrador, uma vez que falam em primeira pessoa e, muitas vezes, surpreendem-se divididos entre traduzir e testemunhar, entre permanecer o profissional neutro, despercebido, anônimo, e ser leal à efêmera comunidade de uma língua que reclama direitos e que é, em vários casos, uma de suas línguas maternas.

Segundo RUTH MORRIS (2010: 20), o sistema legal geralmente exige do intérprete a neutralidade, a faceless voice, mas admite que não é o que ocorre na prática, considerando que os próprios intérpretes veem-se como indo além do estritamente linguístico - no caso da África do Sul, trazem consigo a vivência cultural dos que não têm o inglês como primeira língua e que podem "ter também suas próprias reflexões sobre o que está se passando no processo de que são indiscutivelmente uma parte” (p. 22). Para a autora, a despeito das prescrições e proscrições dos códigos de ética e conduta profissional, os intérpretes - mais especialmente em situações de violações de direitos humanos - "não deixam na porta [da sala da corte, delegacias, comissariados, etc.] sua humanidade"5; prova disso, acrescenta, é que muitos dos que trabalharam na Comissão Sul-africana desistiram e/ou apresentaram sintomas pós-traumáticos (p. 23).

O intérprete não escapa à contingência do que é ouvido, e que diz respeito ao clamor que da voz da vítima e do torturador pode se transmitir, à dor das palavras. Junto com a história que se narra na língua que vai pôr em tradução, vem o inarticulado, o real - eis a dificuldade de traduzir, de dar lugar a esse fora do sentido. Nesse (em) vão, o acontecimento não se diz, e escorre a fala errante, abandonada, escandida pelas contingências... A

\footnotetext{
${ }^{5}$ Quase metade do trabalho da autora é dedicada ao intérprete Erik Camayd-Freixas, um Ph.D. de Harvard, que denuncia a injustiça em um julgamento em massa de estrangeiros ilegais acusados de fraudes em lowa, em maio de 2008. Seu protesto e um artigo sobre o caso foram reportados em The New York Times pela jornalista Julia Preston, em 11 de julho de 2008. http://www.nytimes.com/2008/07/11/us/11immig.html?pagewanted=all\&_r=0 Acesso em julho de 2008.
} 
memória dá voltas, luta contra e pelo esquecimento, interrompe-se, hesita, não se deixa transladar em palavras. A intérprete Khetiwe Marais diz em entrevista a CHRISTINE ANTHONISSEN (2008 p.178):

\begin{abstract}
Algumas vezes, as pessoas estavam atormentadas demais para descrever o que tinha acontecido, e eram incoerentes, então, você não quer imitar [mimic]... mas quer atravessar essa incoerência sem tirar dela sua integridade. Então você tenta não ser claro com palavras claras e conceitos precisos que não vinham dessa pessoa, essa pessoa está desesperada e você tem que deixar passar como essa pessoa também sente nisso tudo 6 ...
\end{abstract}

O papel dos intérpretes é bem definido no Relatório, sublinhando o fato de a Comissão ser itinerante e informando sobre os gastos com os serviços desses profissionais. No volume I, capítulo 11, parágrafo Translation and interpretation services, lê-se:

A Comissão [também] estabelece o precedente para um conceito bastante novo nas estruturas governamentais da África do Sul: a introdução de um serviço de interpretação simultânea. O Ato de fundação possibilita às pessoas, em seu acesso à Comissão, o uso da língua de sua escolha, o que apresentou um interessante desafio para a Comissão, dado o fato de a África do Sul ter onze línguas oficiais. Equipamento especial foi importado da Bélgica e um grupo especial de intérpretes foi recrutado e treinado [inicialmente por membros da ULFE] e depois por um programa da University of the Free State ${ }^{7}$ (p. 298-299)

No mesmo volume, logo nas páginas de abertura (p. 21), há um destaque para a questão levantada por RUTH MORRIS (2010) sobre os intérpretes, incluindo também a equipe de pessoas encarregadas das transcrições:

\footnotetext{
${ }^{6}$ Os tempos verbais foram rigorosamente mantidos nessa tradução.

${ }^{7}$ Os detalhes sobre o recrutamento, seleção e treinamento desses profissionais está descrito em um artigo de CHRISTINE ANTHONISSEN (2008). O contrato foi assinado com a Unit for Language Facilitation and Empowerment (ULFE), que funciona atualmente na mesma universidade, no Departamento of Language Management and Language Practice. Ver também Veras, 2011.
} 
VERAS, V. Quando traduzir é (re)escrever (um)a história

Os intérpretes, por exemplo, tiveram o trauma não somente de ouvir ou ler sobre as atrocidades, mas também de terem tido de falar em primeira pessoa [...] Eles me despiram e abriram uma gaveta $e$ enfiaram meu peito na gaveta e então fecharam a gaveta violentamente em meu mamilo! [ou] Eu tomei seu café e em seguida atirei em sua cabeça. Então queimei seu corpo. Enquanto estávamos fazendo isso, olhando seu corpo queimar, ficamos saboreando um 'braai' [churrasco]...

O chefe da seção que digitava as transcrições das audiências contoume: Enquanto você digita, você não sabe que está chorando até que sente e vê as lágrimas caindo em suas mãos.

\section{As ficções/fixões da verdade ${ }^{8}$}

A abordagem adotada pela Comissão concebia a exposição pública da experiência traumática como libertadora e terapêutica para as vítimas, que não tinham nem os meios intelectuais nem práticos de se opor ao apartheid, uma vez que estavam encerradas em um sistema político no qual a família, a igreja, a escola e todas as instituições promoviam a segregação como modo de vida. Valorizando as verdades das narrativas marginais que desafiam e fragmentam a história oficial, a Comissão pode fazer com elas um futuro alicerçado no reconhecimento de um passado traumático e doloroso. Tratavase de construir esse arquivo do passado e de promover a democracia, que se mede sempre, como diz JACQUES DERRIDA em Mal de arquivo: uma impressão freudiana, segundo a participação e o acesso ao arquivo, à sua constituição e à sua interpretação. Para o filósofo, a questão de uma política do arquivo é a questão política por excelência (2001: 16), uma vez que não há arquivo sem futuro, assim como não há passado morto, o arquivo é então promessa: “o

\footnotetext{
${ }^{8}$ O jogo de palavras é tomado de JACQUES LACAN. Em "O aturdito" (2003), o psicanalista relaciona a ficção à verdade fabricada discursivamente, e nomeia fixão o trauma (real), que não está somente na brutalidade dos eventos relatados, mas naquilo que em cada relato falhas, repetições, interrupções, silêncios - desafia a compreensão.
} 
arquivo sempre foi um penhor, e como todo penhor, um penhor de futuro" ( $p$. 31, grifo do autor).

Considerando o relatório (TRC Report) como arquivo, são precisas as observações de WENDY CORRY E MARTIN TERRE BLANCHE (2000) quanto ao fato de só haver transcrições em inglês, deixando de lado a complexidade do próprio trabalho de tradução, e salientando o fato de que a experiência vivida na língua africana escolhida pela testemunha vai mudar de tons e cores no contexto inglês. $O$ exemplo citado é a transcrição do relato de Gejane Pauline Mbiba, uma sobrevivente cuja história é bastante fragmentada, com sentenças curtas, em staccato, que podem aparecer como incoerências na tradução, quando "a verdade que eles [sobreviventes] contam é baseada em uma forma mais intricada de autorreflexão" (2000: 13). O caso, diz ainda SEAN FIELD (2012), é especialmente delicado na África do Sul, que busca, nos palcos da Comissão, dar voz ao que foi silenciado pelo regime opressor do apartheid racial. Para o autor, os próprios historiadores sul-africanos ainda veem essas narrativas orais (traduzidas e transcritas) como stories, fontes 'nãoprimárias', como suplementos que preenchem alguns vazios da History, essa, sim, baseada em fontes escritas autorais. A força da Grande Narrativa ${ }^{9}$ ainda leva esses historiadores a tomar as memórias narrativas como meras lembranças, imagens que vêm à tona de repente, mesmo admitindo que esses “efeitos inconscientes” são complexos. Contudo, é preciso não esquecer o objetivo maior da Comissão: fazer a paz com palavras; e fazer a paz com as palavras é um ato político e, como afirma BARBARA CASSIN, citando Plutarco (Vida de Solon) em Guerre et réconciliation (2005: 31), "é político cuidar da linguagem [...] e é um bom meio de tirar do ódio a sua eternidade”.

\footnotetext{
${ }^{9}$ Remeto ao que diz JeAn-Françols LYOTARD (2009: 13) em A condição pós-moderna: "O direito de decidir sobre o que é verdadeiro não é independente do direito de decidir sobre o que é justo, mesmo se os enunciados submetidos respectivamente a esta e àquela autoridade forem de natureza diferente".
} 
VERAS, V. Quando traduzir é (re)escrever (um)a história

O título do artigo de Zannie Bock, Ngwanya MazWI, Sifundo Metula e NosisI MPOLWENI-ZANTSI (2006), “An analysis of what has been 'lost' in the interpretation and transcription process of selected TRC testimonies", marca o retorno ao arquivo e às formas como o que se "perdeu" estão registradas pelo erro ou pela falta. Os autores analisam nove excertos de narrativas (original, tradução do intérprete, tradução dos autores e transcrição no site) em que as condições de trabalho dos intérpretes e transcritores, reconhecidamente precárias, vão interferir no estabelecimento da verdade buscada pela Comissão: o fato de haver intérpretes cuja língua materna não era o inglês e exerciam a profissão de forma "não sancionada pela convenção internacional de interpretação" (2006: 4), a barreira dos tabus, o tom marcadamente emocional, a espetacularização da cobertura midiática. Como em outros trabalhos com os arquivos - este e mais um que mostro a seguir -, há um aviso de cuidado com o que se lê nos volumes do TRC Report; recomendação cuidadosa, sem dúvida, e que não se reduz a um cuidado em simplesmente buscar a verdade na língua original. 0 excerto 8 é uma parte do testemunho da Sra. Mhlawuli, no momento em que relata que seu sogro havia identificado o corpo do filho - Sicelo - e as condições em que se encontrava. Os autores observam que na versão da web, além da edição ligada à compreensão dos leitores, o choro da testemunha é eliminado; as repetições de my child, escrupulosamente mantidas pelo(a) intérprete e autores, são excluídas, reduzindo muito a intensidade emocional; a pergunta do comissário é sempre editada, e a compaixão que a expressão facial e a postura corporal do Sr. Smith mostram no vídeo se perde.

TRANSCRIÇÃO XHOSA

MRS MHLAWULI: ... I suppose inokuba zazikhona ne remarks ebabezenza / but baya bafika phaya bajonga / utata wafumanisa ukuba Tyhini! Nguye nyani uSicelo lo / uthi "mntwana wam imeko akuyo" / wandixelela ukufika kwakhe wathi / "mntwana wam imeko akuyo/ iyoyikisa / umntwana wam bamtshisile umntwana wam, umntwana wam bambulele kabuhlungu umntwana wam" [cries] (.4)

MR SMITH: Are you - are prepared to continue Mrs Mhlawuli? 
VERAS, V. Quando traduzir é (re)escrever (um)a história

TRADUÇÃO PARA O INGLÊS (com uma modificação pelos autores)

MRS MHLAWULI: ... I suppose they also made certain remarks / but they went there and looked / my father found that Really! It is him, Sicelo / he says "my child the condition that he is in" / he told me on his arrival and said / "my child the condition that he is in / is frightening ${ }^{10} /$ my child they burned my child / my child, they killed my child horribly" [cries]

MR SMITH: Are you - are you prepared to continue Mrs Mhlawuli?

\section{VERSÃO DO WEBSITE}

MRS MHLAWULI: ... I understand there were also remarks. My father in law had a look and confirmed that one was Sicelo. He said the condition in which he was in was really shocking. They had burned him terribly.

MR SMITH: Are you prepared to continue? (2006: 18-19) ${ }^{11}$

Concluindo as análises, os autores fazem uma ressalva: “deve-se notar, no entanto, que os achados referidos acima não podem ser generalizados para todos os testemunhos", uma vez que são muitos os fatores que podem ter interferido no trabalho dos intérpretes em cada ocasião (2006: 24). A (re)escrita do trabalho do rainbow people ${ }^{12}$ recontextualiza os relatos e também reclama atenção para a tradução audiovisual, tradução como mediação, mas também midiatizada: os arquivos estão no site oficial da TRC,

\footnotetext{
${ }^{10}$ Os autores indicam que a palavra xhosa iyoyikisa havia sido traduzida pelo/a intérprete por "disappointing", e que a pessoa encarregada da transcrição provavelmente considerou-a muito branda para o contexto (2006: 20).

${ }^{11}$ Inglês: Sra. Mhlawuli: ...eu suponho que eles também fizeram alguns comentários / mas eles foram lá e olharam / meu pai achou que Realmente! É ele, Sicelo / ele diz "meu filhinho a condição em que ele está" / ele me contou quando chegou e disse / meu filhinho a condição em que ele está / é assustadora / meu filhinho eles queimaram meu filhinho / meu filhinho, eles mataram meu filhinho horrivelmente" [chora] Sr. Smith: A Sra... a Sra. Está preparada para continuar, Sra. Mhlawuli?

Versão da web: ...eu entendo que houve também comentários. Meu sogro deu uma olhada e confirmou que aquele era Sicelo. Ele disse que a condição em que ele estava era realmente chocante. Eles o tinham queimado terrivelmente. Sr. Smith: A Sra. Está preparada para continuar?

${ }^{12}$ Essa expressão, baseada no símbolo bíblico do arco-íris, foi cunhada por Desmond Tutu, o arcebispo anglicano que dirigiu os trabalhos da Comissão. A expressão já vinha sendo usada por ele com referência ao povo africano como Rainbow Nation, e aparece oficialmente no preâmbulo do primeiro capítulo do vol I do TRC Report, quando se dirige a todos, brancos e | negros, coloureds e indianos, "we this rainbow people of God".
} 
em Yale, no $\mathrm{SABC}^{13}$, além de publicações impressas. Trabalhando a relação tecnologia e cultura, MichaEL CRONIN (2002) tem por foco justamente as formas de preservação e transmissão, e traz como exemplo a África do Sul pósapartheid, seu compromisso com o multilinguismo e suas implicações para os estudos da tradução. O intérprete não interfere somente no componente linguístico, mas em todo o processo que permite a passagem do texto falado para o texto escrito ${ }^{14}$.

\section{O que (não) se traduz}

Penso que é sempre preciso considerar que entre o acontecimento que a vítima se dispõe a relatar em diversas línguas, os membros da comissão, o(a)s intérpretes e outras testemunhas, há um gap no qual se encarna um estranhamento que a distorção, o lapso/erro de tradução, a 'economia' da transcrição impõem ao testemunho. No movimento da transmissão inscreve-se a descontinuidade, interrompe-se a história, e a distorção testemunha, no texto original e/ou no texto transcrito, a falha (fora) da tradução - e pode bem ser que seja em torno dessas distorções que se constrói grande parte das teorias. Falando da internacionalização da tradutologia, MARIA TYMOCZKo (2005: 1087) lembra que a palavra árabe para tradução é tarjam, que é não só associada ao gênero narrativo, como também significa originalmente biografia.

\footnotetext{
${ }^{13}$ Comemorando os 15 anos dos trabalhos da TRC, a South African Broadcasting Corporation, traz reportagens e vídeos nos Special Reports, disponíveis em http://www.sabc.co.za /news/f2/ad2bdb804eb7f4d3aacffa7da4cd6ad7/Remembering-the-TRC-20130228 Acesso em 15 de março de 2013.

${ }^{14}$ Em seu traçado dos rumos da tradutologia, MARIA TYMOCZKO (2005) detecta um movimento de ampliação da área em direção à tradução intersemiótica proposta por Jakobson. Para a autora, o que era antes uma área marginalizada (legendagem e dublagem) vem se tornando a norma.
} 
É o estranhamento provocado pelo testemunho de Notrose Nobomvo Konile, uma das mães dos sete jovens assassinados em março de 1986 pela Polícia de Segurança no incidente nomeado Gugulethu Seven que leva as três pesquisadoras Kopano Ratele, Nosis MpolwenI e ANTJIE Krog (2007) a retornar ao arquivo e tentar escutar de novo o relato da Sra. Konile. Das mães que vêm testemunhar - Cynthia Ngewu, Irene Mtsingwa e Eunice Thembiso Miya - a Sra. Konile é a última, e seu depoimento é considerado incoerente, ininteligível em alguns trechos, enfim, um texto estranho, marcado por rupturas inacessíveis à interpretação, e que vão além da "estranha fatalidade ${ }^{15}$ " de as palavras inglesas e xhosa não coincidirem, deixando lacunas entre si - o que a análise das gravações e transcrições revela é que a estranheza do relato da Sra Konile estava ligada a diversos fatores: diferente das outras mães, morando em área rural, ela não havia visto seu filho na televisão e não recordava o último contato com ele vivo; havia tentado sepultá-lo em sua vila, segundo sua tradição, e o pedido havia sido negado - para ela, era mais importante enterrar o filho ao lado dos ancestrais que na tumba erguida para os sete heróis na Cidade do Cabo. De volta à vila, A Sra Konile perdeu sua casa e passou a viver em extrema pobreza, e é nessa situação que ela comparece para testemunhar. Encontramos, enfim, nesse trabalho, o problema dos caminhos percorridos pelo relato das vítimas: além de erros e lapsos de interpretação e transcrição, há "códigos e referências culturais que não sobrevivem ao processo de interpretação" (2007: 190). De acordo com ANTJIE KROG, entre os fatores que provocaram seu estranhamento em relação a esse texto fragmentado, está sua capacidade de escuta - de pesquisadora, escritora, poeta, jornalista e, mais especificamente, branca e falante de africâner - e a inaudibilidade que o próprio relato da Sra. Konile impunha, quando, por exemplo, fala de um sonho premonitório e, desviando-se do foco na morte do filho, parece mais preocupada em voltar para casa.

\footnotetext{
${ }^{15}$ Retomo aqui o que leio como lamento de JAMES STRACHEY, tradutor de Freud, no prefácio a Os chistes e sua relação com o inconsciente (1905/1989). O tradutor fala das dificuldades de traduzir o alemão de Freud.
} 
VERAS, V. Quando traduzir é (re)escrever (um)a história

Para SANDRA Young (2012), o trabalho com o testemunho da Sra. Konile apresenta-se como uma forma de hospitalidade (no sentido derridiano do termo) oferecida a marginalizados e estranhos, mas acaba por acomodar o relato a um frame interpretativo. Apesar das boas intenções, afirma SANDRA Young, o que o trabalho mostra é a impossibilidade de obter uma coerência em nome seja da hospitalidade, seja da democracia, seja do ubuntu ${ }^{16}$. O que acontece é que essa mãe, diferentes das outras, "recusa a catarse em favor da insistência em sua devastação, de não ser capaz de ser uma pessoa" (2012: 124).

Entendo que, a despeito das discordâncias, as autoras de ambos os trabalhos sustentam suas posições em relação ao arquivo e ao próprio trabalho de pesquisadoras, afinal, no arquivo estão em jogo os conceitos de arkheion (de início a residência dos magistrados) e o archon, o guardião do arquivo que detém o poder de interpretá-lo (JACQUES DERRIDA, 2001). Para cada uma delas, os relatos dos sobreviventes, suas traduções e transcrições não são tomados como dados cuja “dadidade” está garantida - trata-se, como afirma KANAVILLIL RAJAGOPALAN (2011, prelo), de reconhecer que essa coleta é sempre uma interferência e que o contexto é inseparável do dado. Recordemos a preocupação da intérprete Khetiwe Marais em dar lugar à “incoerência” dos relatos, buscando manter sua integridade. Penso que, considerando as reflexões tecidas neste parágrafo, o fato de ANTJIE KROG (2007: 197) confessar: "toda vez que leio o trecho em que a Sra. Konile rejeita os boers sinto-me estranhamente perturbada [unsettled] ${ }^{17}$ " não precisa ser tomado, como o faz SANDRA Young (2012), como mera falência das boas intenções e uma encenação do paradoxo da hospitalidade (JACQUES DERRIDA, 2003). Quanto às escutas do(s) relato(s) dessa mulher, também considero possível, ainda derridianamente,

\footnotetext{
${ }^{16}$ Em língua xhosa, o termo ubuntu (ser com o outro) refere-se ao espírito de solidariedade que preserva a estabilidade do grupo. Para JACQUES DERRIDA (2004: 116), o termo serve para definir a missão da Comissão e para traduzir a própria "reconciliação". Em La douleur des mots, ANTJIE KROG (2004) define-o como o Cogito sul-africano.

17 O trabalho é uma publicação conjunta, mas há partes identificando as questões que mobilizaram cada autora. A palavra unsettled pode ser lida como uma des-colonização, um deslocamento dessa terra que os ancestrais da autora haviam colonizado.
} 
VERAS, V. Quando traduzir é (re)escrever (um)a história

entender a hospitalidade não como uma solução, mas justamente como abertura de uma possibilidade de permitir uma ideia do outro como diferença, como sua diferença - o que é praticamente impossível, afirma JACQUES DERRIDA (2003), mas deve permanecer no horizonte (como faz a intérprete citada há pouco) - oferecer hospitalidade mesmo sabendo que ela tem que ser negociada a cada instante.

\section{How to do things with constitutional words ${ }^{18}$}

Durante os trabalhos da Comissão, o inglês é a língua de tradução (a língua de chegada); não é a língua da imensa maioria das vítimas, além de não ser também a língua materna da maioria dos intérpretes das línguas africanas: quase todos têm línguas maternas diferentes do inglês (Cf. VerAS, 2011). Além do problema de o inglês ser a língua do apartheid e da religião cristã anglicana encarnada na figura do arcebispo Desmond Tutu, há, para JACQUES DERRIDA (2004: 116), não só o perigo de “tomar por natural a tradução dos idiomas africanos”, mas de a tradução da anistia tomar a forma de um perdão condicionado ao arrependimento, ignorando "todas as genealogias culturais e simbólicas que trabalham as palavras", e submetendo o gênio das línguas africanas a um processo geral de cristianização. Trata-se, para o autor, de uma tradução marcada pelo que chamou de uma "violência aculturante, para não dizer colonial, que não se limita a uma questão superficial de retórica, de língua ou de semântica" (2004, p. 137).

A transmissão dos primeiros relatos das vítimas/sobreviventes na Comissão Verdade e Reconciliação sul-africana foi parte do trabalho da então 18 É assim que BARBARA CASSIN (2004: 14 e 44) escreve a proposta austiniana (em How to do
things with words, 1975) no contexto da Comissão da Verdade e Reconciliação sul-africana. 
poeta e jornalista ANTJE KROG ${ }^{19}$ (2004), que fez a cobertura das sessões itinerantes da Comissão para a rádio estatal sul-africana (South African Broadcasting Corporation) durante dois anos, de 1996 a 1998. Transmitidos pelas equipes de radio e televisão, além de jornais e revistas, os relatos e depoimentos atravessaram o país, a diversidade de línguas e de classes sociais, provocando diversos tipos de reação. Com os pedidos de anistia, aparece também a grande dificuldade em lidar com a reconciliação, e é ela o objetivo maior da full disclosure - o perpetrador deve dizer toda a verdade; verdade suficiente para produzir um consenso e (re)escrever a história do povo, e que, como afirma BARBARA CASSIN, “não está aí, sempre dada [...], mas ligada ao tempo, a uma ocasião", enfim, a verdade em jogo na Comissão é uma verdade "não ontológica, porque après coup, e não epistemológica, porque plural” (2004: 45-46).

A palavra "reconciliação", por sua vez, implica, para ANTJIE KROG, a noção de restauração de algo perdido, uma conciliação anterior, razão pela qual essa autora tende a recusar a palavra, trazendo-a no testemunho de Cynthia Ngewu (mãe de Christopher Piet, um dos sete de Gugulethu):

\begin{abstract}
"Essa coisa chamada reconciliação... se estou entendendo bem, se ela significa que esse perpetrador, esse homem que matou Christopher Piet, se isso significa que ele se tornou humano de novo, de modo que todos nós, nós recuperamos nossa humanidade... se é isso, então eu concordo, eu suporto tudo". (ANTJIE KROG, 2004: 150)
\end{abstract}

Há uma resistência à verdade e à reconciliação. Segundo GRAHAME HAYES (1998: 46), os perpetradores resistem à verdade que faz deles culpados ou cúmplices; as vítimas temem a verdade pela dor que traz, mas também porque traz com ela "essa coisa chamada reconciliação". 0 autor lembra que um dos banners nos cenários da Comissão dizia: Just revealing in not healing, o que significava dizer que a cura [healing] dependia não só da revelação [revealing], mas do como, do contexto e do que era revelado; diretrizes cuja

\footnotetext{
${ }^{19}$ Falo do livro La douleur des mots, traduzido do inglês sul-africano Country of my skull:
} guilt, sorrow and the limits of forgiveness in the New South Africa (ver referências). 
ênfase nos valores cristãos e no perdão, sugeriam - senão impunham escolher perdoar.

RebecCA SAUnders (2008) discute pontualmente a impossibilidade de traduzir o sofrimento das vítimas na linguagem dos Direitos Humanos, embora admita que, mesmo padronizada e universal, essa linguagem possibilitou o reconhecimento de eventos da história traumática da África do Sul e a identificação das vítimas. A crítica da autora refere-se mais especificamente ao fato de que a memória traumática "não respeita a racionalidade própria dos princípios de direitos humanos" (p. 54) e exibe a falta de relevância de grande parte dos relatos das vítimas. A autora toma tradução, no sentido amplo, como tradução "forçada" do sofrimento para "a linguagem austera dos direitos" (p. 54), mas toma por "natural” (uma tradução entre outras) o trabalho dos tradutores e intérpretes, sequer mencionado.

A despeito da falta de preparo mais técnico de muitos dos intérpretes ${ }^{20}$, nem sempre os equívocos estavam relacionados à fluência de cada um em uma ou outra(s) língua(s). Os intérpretes de línguas africanas falavam em geral três ou quatro línguas - Khetiwe Marais fala todas as línguas oficiais, e conta em uma entrevista ${ }^{21}$ que o mais difícil era suportar a dor das palavras que atravessavam sua voz, sem the darem chance de escolher as mais adequadas, sem contar aquelas que permaneciam muitas vezes irredutíveis, reclamando sua assimetria. Mas o problema não se reduz a algo como traduzir o indizível, como diz ainda a intérprete, mas de não haver palavras na língua (não vive nela a racionalidade reclamada por REBECCA SAUNDERS para os princípios dos direitos humanos): "Nós criamos o vocabulário da TRC [...] Se surge uma palavra nova, ou você lida com o conceito (faz uma paráfrase) ou lida com o lado emocional da palavra (e oferece uma conotação)". Nada disso está previsto no treinamento profissional do(a) intérprete, simplesmente porque - acrescento, seguindo JEAN-LUC NANCY - diz respeito ao que não se

\footnotetext{
${ }^{20}$ Cf. Christine Anthonissen, 2008.

${ }^{21}$ Essa entrevista com vários intérpretes da Comissão foi gravada pelo grupo que montou o musical Truth in translation, e está disponível em <http://vimeo.com/1112108> Acesso em junho de 2011.
} 
transmite pela via dos sentidos, ao que não é inteligível, e apenas ressoa, “aquém de um dizer, de um 'querer-dizer' [...] com valor de um proferimento ainda sem intenção" (2002: 53), e é preciso pôr-se à escuta.

\section{Until the lions have their historians, tales of history will always privilege the hunter ${ }^{22}$}

Em “O Narrador”, ensaio de 1936 publicado em Magia e técnica arte e política: ensaios sobre literatura e história da cultura, WALTER BENJAMIN (1994) afirma que na ficção-construção d(um)a história encontra-se nas narrativas o valor de transmissão, de experiência que passa de pessoa para pessoa. 0 narrador pode "recorrer ao acervo de toda uma vida", à própria experiência, mas também à alheia, "assimilando à sua substância mais íntima aquilo que sabe por ouvir dizer" (p. 221). Ancorada na oralidade e no tempo presente, na ocasião oportuna, Benjamin instaura o narrador no centro daquilo "que ele retira das experiências que conta [...] e incorpora à experiência dos ouvintes" (p. 201). Além disso, o ouvinte "é livre para interpretar a história como quiser, e com isso o episódio narrado atinge uma amplitude que não existe na informação" (p. 203). Nas inspiradas palavras de JEANNE MARIE GAGNEBIN em seu prefácio a essa obra de Benjamin, trata-se "da transmissão de uma experiência no sentido pleno" de "um saber, uma sapiência, que seus ouvintes podem receber com proveito" (p. 11). No contexto da Comissão sul-africana, que recupera na modernidade o valor desse tipo de transmissão, os intérpretes são uma espécie de 'tradutores do passado', no sentido que MÁrCIO SeligmanN-Silva (2003: 64) dá a essa tarefa, em des-encontro endividado com o original, mas que pode deixar o que considero um saldo positivo: nada do que

\footnotetext{
${ }^{22}$ Provérbio africano.
} 
um dia aconteceu pode - daí em diante - ser considerado perdido para a história.

No palco da Comissão, a distribuição dos papéis não é fixa, e é a urgência em atender a todos os pedidos que se impõe e tende a fixá-los. LIETITIA BUCAILLE (2007: 316) chama a atenção para o tratamento dado aos que vêm testemunhar, muitas vezes marcado pela compaixão e que termina por acentuar muito precisamente o papel de vítimas e dando atenção menor ao ato de coragem que foi para cada uma comparecer frente à Comissão e contar sua história. Para a autora, a categoria binária torturador-vítima altera o viés político da luta das militantes, das mulheres que haviam participado ativamente das lutas anti-apartheid. Enfim, entre as escuras duas margens de cada verdade em tradução, elas "correm o risco de se tornarem prisioneiras de uma identidade vitimada e, consequentemente, privadas dos frutos de sua própria vitória” (p. 317).

Na construção desse passado, a distribuição dos papéis e a instituição do arquivo implicam o que JACQUES DeRRIDA (2001: 29) chamou de função patriárquica, que se mostra no dispositivo de anistia como dispositivo irônico. Como lembra BARBARA CASSIN, essa ironia está no fato de que em um processo normal o acusado fala o menos possível, enquanto na Comissão ele deve dizer tudo, toda a verdade, full disclosure, ou não será anistiado: “o interesse do perpetrador se confunde com os interesses da nova comunidade [...] por meio de suas revelações, eles fabricam o passado comum, eles se tornam, de certa maneira, pais fundadores - os perpetrators" (2004: 50-51). o único tributo pago pelo perpetrador - e que parece pouco, considerando os que não compareceram e os que mentiram - é que essa anistia não implica a amnésia jurídica. O depoimento (account) do perpetrador é tomado por PHILIPPE-JOSEPH SALAZAR (2002) como um ato de fala que se revela paradoxalmente patriótico, uma vez que exercendo a função patriárquica, ele vem atestar o novo patrimônio, a nova democracia pós-apartheid, o almejado bem comum alcançado por todos aqueles que recusaram essa política de separação. 0 
Perpetrador é aquele "que foi até o fim $^{23}$ ", até o crime, para manter-se ligado ao patrimônio do apartheid.

Com todos os defeitos apontados principalmente em trabalhos mais atuais, que denunciam as falhas no processo de Reparação, a proposta da Comissão da Verdade e Reconciliação não se oferece como uma volta ao passado. O passado terá sido escrito no presente, permitindo apreender o antes e o depois do totalitarismo do apartheid, e funcionando como um corte temporal, o kairós, a ocasião, o momento oportuno para uma abertura política.

\section{Somente a árvore resistia a nosso eterno fluxo ${ }^{24}$}

Tree partilha com Truth o mesmo radical. PHILIPPE-JOSEPH SALAZAR (2004: 59-60) traduz truth pelo saxão triew, que quer dizer fidelidade, confiança, que implica a ideia de troca. Na linhagem que reconstrói, chega ao indoeuropeu *dru-, onde encontramos a árvore símbolo da garantia da palavra dada, viva na sabedoria do druida. 0 autor apresenta, então, as verdades em jogo na Comissão: a verdade judiciária (forensic truth); a verdade narrativa (narrative/personal truth, truth telling, storytelling); a verdade social (social truth) e a verdade-cura (restorative, healing truth) (p. 61). Essas verdades em tradução não se elegem, portanto, como a verdade, e o que se põe em cena no palco da Comissão é também a forma como os intérpretes questionam

\footnotetext{
${ }^{23}$ Perpetrator (do radical pəter-, per+patrāre) é o que executa, que consuma, e também o que porta a fala do pater patratus, o enviado, o encarregado da paz (Cf. American Heritage Dictionary).

${ }^{24}$ Fala de Bernard, em The Waves de VIRGINIA WOOLF, traduzida por Flavia Trocoli (The tree alone resisted our eternal flux).
} 
muitas verdades, as traduções de forgiveness, as formas como lidam com as dores postas em palavras, gemidos, silêncios.

Depois de ouvir no relato de Babalwa, filha de Sicelo Mhlawuli (um dos chamados Quatro de $\left(r a d o c k^{25}\right.$ ), a mais extrema violência, ANTJIE KROG afirma: “nenhum poema deveria sair dessa experiência... que me cortem a mão se eu o escrever” (2004: 75). Mas é justamente um poema que é anunciado no final do livro: "vejo minha mão escrever, por todos nós, todas as vozes, todas as vítimas", e leio ali um poema ${ }^{26}$, talvez o que JACQUES DERRIDA chamou de speech act, "um gesto pelo qual se oferece ou propõe a reconciliação estendendo a mão" (2004: 111).

Caminho para o final deste trabalho retomando suas metáforas teatrais: o palco da Comissão, os atores, os bastidores revelados em diversos trabalhos de pesquisadores - antropólogos, linguistas, artistas, historiadores, críticos literários, ativistas... - a mídia, o apelo ao performativo, o papel dos intérpretes de línguas. Menciono, então, duas das principais peças teatrais que nasceram das histórias do arquivo e que também reescrevem, como arte, como ficção, a história da África do Sul.

MichAel LesSAC, diretor do musical Truth in Translation, disse em entrevista $^{27}$ recente que a ideia para a peça veio justamente de sua consideração do papel teatral dos intérpretes, e conta como as plateias, em diferentes países, reagiram de formas diferentes - fosse criticando o fato de trazer a bela música do maestro e compositor africano Hugh Masekela (como musicar com beleza tantos horrores?), fosse criticando momentos de humor

\footnotetext{
${ }^{25}$ Matthew Goniwe, Sparrow Mkhonto, Fort Calata e Sicelo Mhlawuli, ativistas anti-apartheid, foram sequestrados por policiais brancos das forças de segurança e tiveram seus corpos queimados no dia 27 de junho de 1985.

${ }^{26}$ Esse poema também faz parte do relatório, do arquivo que registra e rasura a história da África do Sul.

27 Entrevista concedida ao German Council on Foreign Relations (DGAP) em novembro de 2011. Disponível em https://ip-journal.dgap.org/en/article /15458/print. Acesso em março de 2013. Mais detalhes sobre a peça em http://www.truthintranslation.org/
} 
(como brincar com coisas tão sérias), mas sempre participando dos workshops propostos pelo grupo.

Retomando o subversivo Ubu Rei (1896), JANE TAYLOR vai combinar a farsa do original de Alfred Jarry com a terrível sobriedade dos testemunhos na Comissão da Verdade durante o ano de 1996. O que atrai a autora no trabalho da Comissão é justamente o fato de história e biografia estarem mescladas nos testemunhos. A peça Ubu and the Truth Commission, em colaboração com William Kentridge (diretor da peça) e a Handspring Puppet Company, explora a complexidade das relações na Comissão, a teatralidade da representação das audiências e as consequências disso - a peça alude ao fato de a divulgação midiática influir no próprio trabalho que ali se realizava.

Criação multimídia com animação, bonecos (vítimas) e atores humanos (perpetradores) - estreou em Johannesburg em 1997. Com trilha sonora mesclada de raps e hinos, falas em africâner, zulu, xhosa e inglês - com traduções $^{28}$ e projeções de sequências cinematográficas. Pa Ubu é um perpetrador do apartheid preparando-se para aparecer na Comissão, e a versão do full disclosure de Pa Ubu torna-se outra mentira contada para o benefício de outros e dele mesmo, expondo a fragilidade dos conceitos de verdade e de reconciliação. Pa Ubu é uma figura que atrai o olhar da plateia e, assim, solicita uma identificação com o torturador, produzindo desconforto. No artigo "For an ethic of discomfort" (2000), Michael FoucaulT traz de volta o mal-estar freudiano, fazendo dele uma categoria produtiva, mas alertando para o fato de que não se trata de um mal-estar como negação do bem-estar, mas como um estranho processo em que não se permanece mais o mesmo.

Nas palavras de ANTJIE KROG (2004: 21), “as narrativas por si mesmas são suficientes para justificar a existência da Comissão. Graças a essas narrativas,

\footnotetext{
${ }^{28} \mathrm{Na}$ versão original, os bonequeiros, como os intérpretes nas sessões realizadas na Comissão, nunca falavam por si mesmos.
} 
as pessoas não podem mais deliciar-se em suas dinastias distintas de denegação". A via escolhida pela África do Sul para traduzir e (re)escrever sua história é a via do ubuntu, palavra que permanece de certa forma intraduzível e aberta a outras traduções. 


\section{Referências bibliográficas}

ANTHONISSEN, CHRISTINE. On interpreting the interpreter - experiences of language practitioners mediating for TRC. Journal of Multicultural Discourses, 2008, 3(3): 165-188.

Austin, John Langshaw. How to do things with words. 2. ed. Cambridge: Harvard University Press, 1975.

Benjamin, WALTER. O narrador: considerações sobre a obra de Nikolai Leskov. In: Magia e técnica, arte e política: ensaios sobre literatura e história da cultura. Tradução de Sérgio Paulo Rouanet, 1994, p. 197-221.

BLASER, THOMAS et al. "Raça", ressentimento e racismo: transformações na África do Sul. Cadernos Pagu, Campinas, 2010, n. 35, p. 111-137.

Bock, Zannie; MazWI, Ngwanya; Metula Sifundo; Mpolweni-Zantsi, Nosisi. An analysis of what has been "lost" in the interpretation and transcription process of selected TRC testimonies. Stellenbosch Papers in Linguistics PLUS, Vol. 33, 2006, 1-26

BuCAILle, LfeTITIA. Vérité et réconciliation en Afrique du Sud - Une mutation politique et sociale. Politique étrangère 2/2007, p. 313-325. Disponível em http://www.cairn.info/revue-politique-etrangere-20072-page-313.htm Acesso em outubro de 2011.

CAMAYD-FREIXAS, ERIK. Interpreting after the Largest ICE Raid in US History: A Personal Account. Artigo enviado a The New York Times em 13 de junho de 2008 (link na página da reportagem de Julia Preston)

CAssin, BARBARA. Guerre et réconciliation. L'exemple de la TRC. Journal de philosophie à l'UNESCO, 2005, p. 21-31.

CASSIN, BARBARA. Amnistie et pardon: pour une ligne de partage entre éthique et politique. In: Cassin, Barbara; CaYla, Olivier; Salazar, PhilipPe-JosePh. (dir.) Vérité, reconciliation, reparation. Paris: Seuil, 2004, p. 37-57.

CorRY, Wendy \& Terre Blanche, MARTIN. Where does the Blood come from? : True Stories and Real Selves at the TRC Hearings. PINS (Psychology in society), 2000, 26, 6-17.

Cronin, MiCHAEL. Babel's Standing Stones: Language, Translation and the Exosomatic. Crossing - Electronic Journal of Art and Technology, 2002, vol 2, $\mathrm{n}^{\circ} 1$. Disponível em http://crossings.tcd.ie/issues/2.1/Cronin/ Acesso em 18 de agosto de 2012.

DERRIDA, JACQUES. Versöhnung, ubuntu, pardon: quel genre? In: CASSIN, BARBARA; Cayla, Olivier; Salazar, Philippe-Joseph. (dir.) Vérité, reconciliation, reparation. Revue semestrielle Le genre humain. Paris: Seuil, 2004, v. 43, p. 111-156. 
VERAS, V. Quando traduzir é (re)escrever

DERRIDA, JACQUES. Mal de arquivo: uma impressão freudiana. Tradução de Cláudia de Moraes Rego. Rio de Janeiro: Relume-Dumará, 2001.

DERRIDA, JACQUES. Anne Dufourmantelle convida Jacques Derrida a falar da hospitalidade. Tradução de Antonio Romane. São Paulo: Escuta, 2003.

FIELD, SEAN. The Politics of Disappointment: Trauma, 'healing' and regeneration in post-apartheid South Africa. In Oral History, Community, and Displacement, 2012. Disponível em http: / /www.riehr.

com.ar/archivos/Investigacion/PoliticsofDisappointment.pdf Acesso em março de 2013.

FoucAult, Michel. For an ethic of discomfort [1979]. In J. FAUBion (ed.). Tr. Robert Hurley and others. Power The Essential Works of Michel Foucault 1954-1984. New York: New Press, 2000, v. 3, p. 444-448.

- Gagnebin, Jeanne Marie. Prefácio. In: Benjamin, Walter. Magia e técnica, arte e política: ensaios sobre literatura e história da cultura. Tradução de Sérgio Paulo Rouanet. São Paulo: Brasiliense, 1994.

Hayes, Grahame. We Suffer Our Memories: Thinking About the Past, Healing, and Reconciliation. American Imago, 1998, 55/1:29-50.

KROG, ANTJIE. La douleur des mots. Tradução de Georges Lory (do ingles sulafricano Country of my skull: guilt, sorrow, and the limits of forgiveness in the New South Africa 1998). Arles: Actes-Sud, 2004.

KROG, ANTJIE; MPOLWENI, NosisI. Archived Voices: Refiguring Three Women's Testimonies Delivered to the South African Truth and Reconciliation Commission. Tulsa Studies in Womens' Literature, 2009, v. 28, n. 2, p. 357-374.

LACAN, JACQUES. O aturdito. In: Outros Escritos. Tradução de Vera Ribeiro. Rio de Janeiro: Jorge Zahar, 2003, pp. 448-497.

LotRIET, ANNelie. Sign Language Interpreting in South Africa: Meeting the Challenges. Critical Link, 2001, vol 2. Disponível em http://criticallink.org/?s=lotriet Acesso em agosto de 2011.

LYOTARD, JEAN-FRANÇOIS. A condição pós-moderna. Tradução de Ricardo Corrêa Barbosa. Rio de Janeiro: José Olympio, 2009.

- Maree, Cathy. Resistance and remembrance: Theatre during and after dictatorship and apartheid. South African Theatre Journal, v. 12, no 1-2, 1998, p.

MORRIS, RUTH. Images of the court interpreter Professional identity, role definition and self-image. Translation and Interpreting Studies 5:1 (2010), 20-40.

Nancy, JeAn-Luc. À l'écoute. Paris: Galilée, 2002. 
VERAS, V. Quando traduzir é (re)escrever

- Preston, Julia. An Interpreter Speaking Up for Migrants. The New York Times, publicado em 11 de julho de 2008. Disponível em http://www.nytimes. com/2008/07/11/us/11immig.html?pagewanted $=$ all\&_$r=0$ Acesso em julho de 2008.

Rajagopalan, Kanavillil. A dadidade dos ditos dados na/da pragmática. In: GonÇALVES, AdAIR; GoIs, MARCos Lócio (Orgs.). Linguística e as várias vertentes: como fazer pesquisa na área da linguagem, Campinas: Mercado de Letras, 2011 (no prelo).

Ratele, Kopano; Mpolweni-Zantsi, Nosisi; Krog, AntJie. Ndabethwa lilitye: Assumption, translation and culture in the testimony of one person before the South African Truth and Reconciliation Commission. Tydskrif Vir Letterkunde, 44 (2), 2007, p. 189-204.

SALAZAR, PhILIPPE-JOSEPH. Une conversion politique du religieux. In: CASSIN, Barbara; Cayla, Olivier; Salazar, PhilipPe-Joseph. (dir.) Vérité, reconciliation, reparation. Paris: Seuil, 2004, pp. 37-57.

Salazar, PhilipPe-Joseph Perpetrator, ou de la citoyenneté criminelle. Rue Descartes. Collège international de Philosophie, 2002, vol. 2, n. 36, pp. 167-179.

SAUNDERS, ReBECCA. Sobre o intraduzível: sofrimento humano, a linguagem de direitos humanos e a CVR da África do Sul. Tradução de Thiago Amparo. SUR - Revista Internacional de Direitos Humanos, 2008, ano 5, número 9 , p. 53-75.

Seligmann-Silva, Márcio. Reflexões sobre a memória, a história e o esquecimento. In: SELIGMANN-SILVA, MÁRCIO (org.) História, memória, literatura: o testemunho na era das catástrofes. Campinas, SP: Editora da Unicamp, 2003, pp. 59-88.

Strachey, James. Prefácio. In Freud, Sigmund, El chiste y su relación con lo inconciente [1905]. Org. com. e notas de James Strachey com a colaboração de Anna Freud. Trad. direta do alemão de José L Etcheverry. Obras completas: Sigmund Freud v.8. Buenos Aires: Amorrortu, 1989.

TAYLOR, JANE. UBU and the Truth Commissions, London: Juta Academic, 1998.

The American Heritage Dictionary of the English Language. New York: Houghton Mifflin Company, 2000.

Truth And Reconciliation Of South Africa. Report, 1998. Disponível em http://www.doj.gov.za/trc Acesso em agosto de 2008.

TYMoczko, MARIA. Trajectories of Research in Translation Studies. Meta: journal des traducteurs / Meta: Translators' Journal, v. 50, no 4, dez. 2005, p. 1082-1097.

Veras, Viviane. Verdade em tradução: um testemunho da dor das palavras. Trabalhos em Linguística Aplicada - TLA, 2011, vol. 50, n.2, p. 459- 
478.

Disponível

em:

<http://www.scielo.br/scielo.php?script=sci_arttext\&pid =S0103$18132011000200014 \&$ lng $=$ pt\&nrm=iso\&tlng=pt $>$

WOOLF, VIRGINIA. The Waves. Londres: Penguin, 1992.

Yale SCHOOL OF LAW. The South African Truth and Reconciliation Commission Videotape Collection, organizada por Max Du Preez. Disponível em: <http://trc.law. yale.edu/video_episodes.htm> (julho/2008).

Young, SANDRA. Hospitality and the Politics of Evidence in a Post-Apartheid Archive: Critical Reflections on There Was This Goat and the challenge of alterity'. Research in African Literatures 43.2, 2012, p. 115-137. Disponível

em: <http://www.humanities.mcmaster.ca/ english/JDT/ archiveandeverydaylife/young.html> (abril/2013). 